\title{
Oviposition behavior of Zabrotes subfasciatus females (Coleoptera, Bruchidae) under conditions of host deprivation
}

\author{
Luzia Aparecida A. Sperandio \& Fernando Sérgio Zucoloto
}

Departamento de Biologia, Faculdade de Filosofia, Ciências e Letras de Ribeirão Preto, Universidade de São Paulo, Av. Bandeirantes,

3900, 14040-901, Ribeirão Preto, São Paulo, Brasil. (zucoloto@ffclrp.usp.br)

\begin{abstract}
Oviposition of Zabrotes subfasciatus (Boheman, 1833) on Phaseolus vulgaris (Linnaeus, 1753) was studied immediately after emergence of the adults throughout the females life and in situations of host deprivation lasting for 1 to 10 days. The number of eggs laid daily, longevity, duration of oviposition and distribution of eggs per grain were studied. The number of eggs laid per day varied significantly, with the oviposition peak in the presence of the host (control group) occurring between day 2 and day 5 of oviposition. In the absence of the host, a shift in the oviposition peak to the first day after deprivation was observed, except for the group deprived for one day which showed a peak between days 1 and 4 after introduction of the host. The distribution of the eggs per grain in the control group and in the groups deprived of the host for 2, 5, 8 and 10 days, a larger egg aggregation was observed for all deprived groups compared to the control group.
\end{abstract}

KEYWORDS. Leguminosae, oviposition behavior, Bruchidae, egg aggregation.

\section{INTRODUCTION}

Oviposition behavior has been the subject of many studies on ecology and evolution of insect-plant interactions (Thompson \& PelLmyr, 1991). This behavior involves characteristics of the adult and immature insects that influence host changes and, consequently, the way how the insect species have been distributed among plants through evolution (THOMPSON, 1988).

Most bruchids found in warehouses are able to reproduce on a wide variety of seeds but, because few legume species are produced commercially on a large scale, each bruchid species is generally considered to be the typical consumer of a particular type of seed (HowE \& CURRIE, 1964). The larval forms of coleopteran Zabrotes subfasciatus (Boheman, 1833) are unable to select food since their entire development occurs within a single grain (bean seeds) (CREDLAND \& DENDY, 1992). Bruchidae is characterized by larvae that feed on the seeds and pods of growing plants (HowE \& CURRIE, 1964). In contrast to many other bruchids, Z. subfasciatus females do not attach their eggs on the pod (PIMBERT, 1985), but require contact with the seeds to stimulate ovarian production and to induce oviposition activity (PIMBERT \& PIERRE, 1983).

In Bruchidae, the adult weevil commonly lays and attaches eggs individually to the bean surface in an apparently random manner (UTIDA, 1967). Z. subfasciatus females lay some of their eggs on the grain surface in groups of 2 or more eggs (UTIDA, 1967). This pattern of oviposition is rarely found in insects that feed on stored seeds and, even so, in the species studied, this habit is not as strong as observed for butterflies and moths (UTIDA, 1967).

The egg load of females (number of mature ovules in the ovaries) is considered an important factor in relation to oviposition behavior (MINKENBERG et al., 1992). Certain behavioral characteristics are influenced by the egg load, including the persistence with which females forage in oviposition sites, the probability of a host to be accepted once found, and the number of eggs laid by a female (Aluja et al., 2001). Pro-ovigenic insects as $Z$. subfasciatus emerge with all eggs mature (MinKENBERG et al., 1992), while in synovigenic species egg maturation occurs throughout the female's life and might depend on climate, time of day, age of the female, previous copulation experience, male contribution with nutrients present in the ejaculatory duct, capacity of egg storage, and adult nutrition (LeATHER, 1984; MinKENBERG et al., 1992). Host deprivation immediately after adult emergence has different consequences for pro-ovigenic and synovigenic species because egg resorption might occur during the period of host deprivation (FLEURY \& BOULÉTREAU, 1993). Since egg production is a continuous process in synovigenic species, the consequence of egg resorption may be milder (VAN LENTEREN et al., 1987). In pro-ovigenic species, however, egg resorption can markedly reduce fecundity since eggs are not replenished (Fleury \& Boulétreau, 1993).

The objective of this study was to analyze the oviposition behavior of wild Z. subfasciatus females throughout both presence or deprivation of host.

\section{MATERIAL AND METHODS}

The infected beans, collected from warehouses in Ribeirão Preto and Paineiras (Minas Gerais, Brazil), were taken to the laboratory and placed in closed acrylic containers $(11 \times 11 \times 3 \mathrm{~cm})$ until adult emergence. The adults were transferred to similar boxes containing beans for rearing in the laboratory. After one generation in laboratory, the experiments were started.

Phaseolus vulgaris L., c.v. rosinha, was used for both supply of $Z$. subfasciatus and for the experiments. This variety was chosen because it is common in the region where the wild insects populations were collected, avoiding host rejection (TeiXeIRA \& Zucoloto, 2003). 
Recently emerged insects, from 0 to $24 \mathrm{~h}$ of age, were used in all experiments.

The rearing of the insects and the experiments were carried out in wooden incubators $(90 \times 50 \times 30 \mathrm{~cm})$ with constant temperature of $29 \pm 2^{\circ} \mathrm{C}$ and relative humidity of $70-80 \%$. Cylindric transparent glass tubes of $7.0 \mathrm{~cm}$ in length and $2.7 \mathrm{~cm}$ in diameter were used for isolation of the couples in pre-established numbers of individuals and quantities of beans. The glass flasks were covered with gauze attached with an elastic.

One test was conducted that yielded several data. Firstly, the mean number of eggs laid per day by the control group (not deprived of host) was compared with the experimental groups which were deprived of host for periods ranging from 1 to 10 days after emergence. Secondly, the longevity and duration of oviposition period of non-deprived and deprived females were measured. Eleven groups were formed, each group containing one recently emerged $Z$. subfasciatus couple and 5 rosinha bean grains. This quantity of beans was chosen since it was found to be ideal for one female (TeixeIRA \& Zucoloto, 2003). Only the control groups received host every day, whereas the experimental groups were deprived of host for 1 to 10 days, respectively. Each period of deprivation was denominated level 1 to 10 , respectively, and 15 replicates were carried out for each group. The grains were changed daily until the death of all females. The beans were kept in smaller glass flasks. The eggs were counted after the 5th day of oviposition when they were opaque and easily visible to the observer naked eye (CARVALHO \& RosSETtO, 1968).

Thirdly the distribution of eggs per grain was compared for females which received host every day and females deprived of host. Five groups were used. Group 1 was not submitted to host deprivation, whereas the other groups were deprived of host for 2, 5, 8 and 10 days, respectively.

The experimental data were analyzed by the Friedman test for comparison of more than two dependent samples and by the Kruskal-Wallis test for comparison of more than two independent samples, with the significance level set at $\alpha=0.05$, using the SigmaStat for Windows statistical program, San Rafael, Jandel Corporation, CA.

\section{RESULTS}

Daily egg production by control females throughout their life was analyzed by the nonparametric Friedman test $(=0.05)$. The peak of oviposition of the control group occurred between days 2 and 5, with oviposition declining to 0 by day 11 (fig. 1). The peak of oviposition of females deprived of host for one day was observed between days 2 and 5 (fig. 2). The peak of oviposition of females deprived of host for 2 to 10 days was always observed on oviposition day 1 after the introduction of host (figs. 3-11). A decrease in total egg production occurred with increasing deprivation, but this difference was only significant from level 6 onwards. The duration of oviposition period was longer in the control group than in the experimental groups; except for level 10 (fig. 11) in which duration was longer but number of eggs laid was smaller.

Longevity tended to increase in groups deprived of host in comparison with the control group (fig. 12). The reduced longevity at level 7 was due to the fact that many females had died before the introduction of host.

With respect to the distribution of eggs per grain in the control group and in the groups deprived of host for 2, 5, 8 and 10 days, a larger egg aggregation was observed for the experimental groups deprived of hosts. Comparison of these groups in terms of the number of grains with 4 or more eggs on oviposition day 1 showed a larger egg aggregation for the groups deprived for 5 and 8 days as compared to the control group and the other groups (tab. I). Comparison of the groups in terms of the number of grains with one or no egg on oviposition day 1 revealed a larger number of grains in the control group and in the groups deprived for a longer period of time ( 8 and 10 days) (tab. I). These results show that host deprivation leads to an aggregated distribution of eggs, while in the daily presence of host, females distribute their eggs more uniformly. In the control group, the highest aggregation frequency was observed on the first days of life of the females and mainly during the peak of oviposition (2nd to 5th day). Groups with more than 4 eggs were only observed at the beginning of the adult phase of the females. In the groups deprived for 5 and 10 days, a larger number of aggregated eggs was only observed on oviposition day 1 , decreasing thereafter. Groups with more than 4 eggs were only present on the first day of oviposition.

Table I. Comparison of the number of egg-containing grains on the first day after host introduction between the control group and the groups deprived of host for different periods of time. The results are reported as mean \pm standard deviation $(X \pm S D)$ of 15 females. Values followed by different letters in the same row were significantly different $(\mathrm{P}<0.05$, Kruskal-Wallis test, $=0.05)$.

\begin{tabular}{lccccc}
\hline Grains & Control & \multicolumn{4}{c}{ Days without host } \\
\cline { 3 - 6 } & & 2 & 5 & 8 & 10 \\
\hline $\begin{array}{l}\text { with 1 or } \\
\text { no egg }\end{array}$ & $4.2 \pm 1.1 \mathrm{a}$ & $2.1 \pm 1.2 \mathrm{~b}$ & $1.9 \pm 1.3 \mathrm{~b}$ & $2.6 \pm 1.9 \mathrm{ab}$ & $2.7 \pm 1.7 \mathrm{ab}$ \\
$\begin{array}{l}\text { with 4 or } \\
\text { more eggs }\end{array}$ & $0.2 \pm 0.4 \mathrm{a}$ & $1.0 \pm 0.6 \mathrm{ab}$ & $1.6 \pm 1.0 \mathrm{~b}$ & $1.2 \pm 1.0 \mathrm{~b}$ & $1.1 \pm 0.9 \mathrm{ab}$ \\
\hline
\end{tabular}

\section{DISCUSSION}

In the present study, the oviposition peak of $Z$. subfasciatus was always observed on the days immediately after introduction of host in both the control group and the experimental groups, confirming observations by Howe \& CURRIE (1964), who reported that adults of this species are sexually mature, being ready for copulation immediately after emergence, and females normally lay their eggs at the beginning of adult life, with the peak of oviposition being reached within a few days and oviposition rates declining thereafter. This finding suggests a tendency for $Z$. subfasciatus females to lay most of their eggs at the beginning of the oviposition period, since they present a short life cycle and, consequently, a higher probability of suffering risks such as predation or competition if oviposition occurs later. 

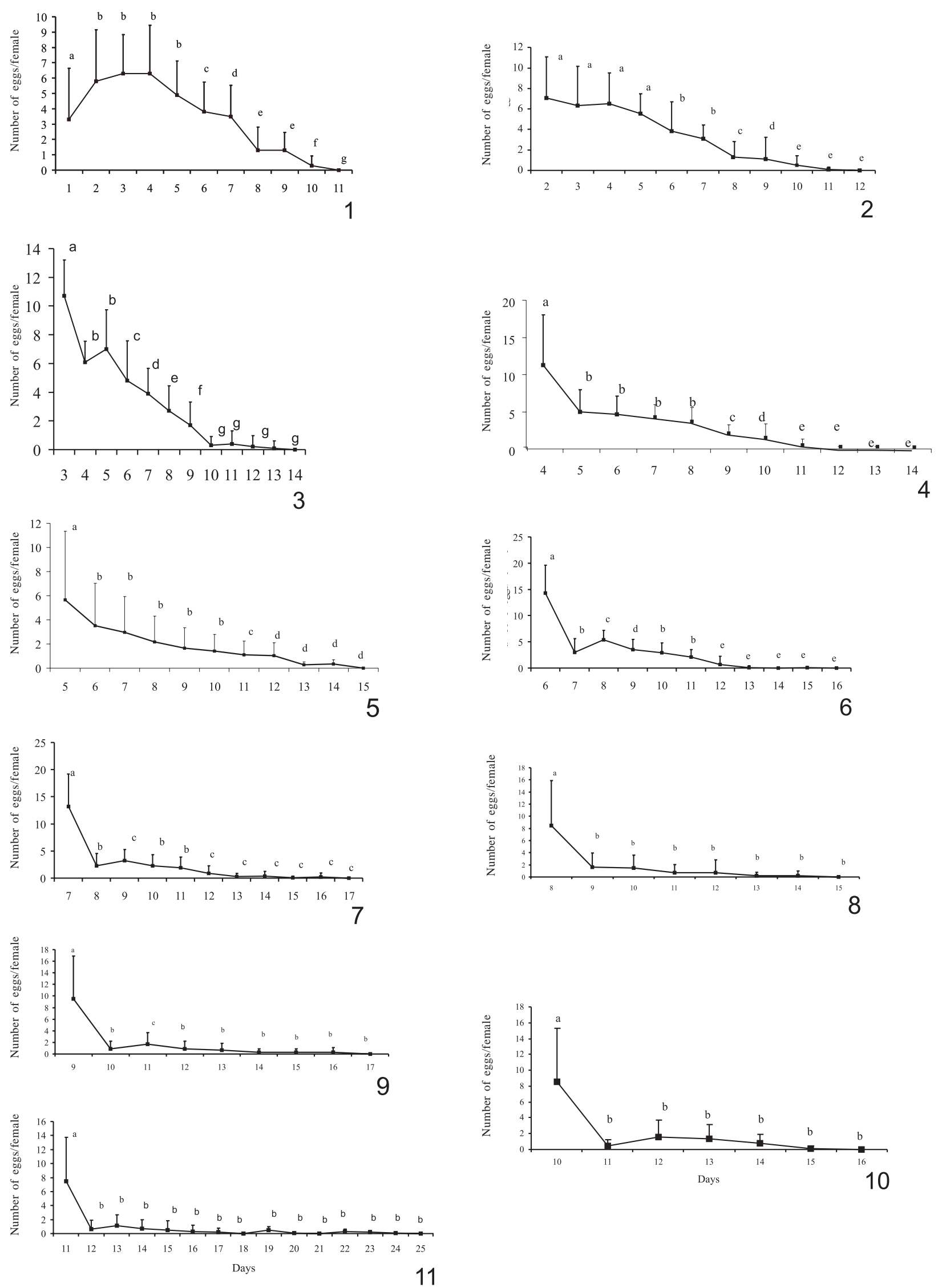

Figs. 1-11. Number of eggs/female produced per day by Zabrotes subfasciatus females deprived of host for 0 to 10 days, respectively. The results are reported as mean \pm standard deviation of 11 groups with 15 replicates $(\mathrm{P}<0.05$, Friedman test, $\alpha=0.05)$. Values followed by different letters differed significantly from each other. 


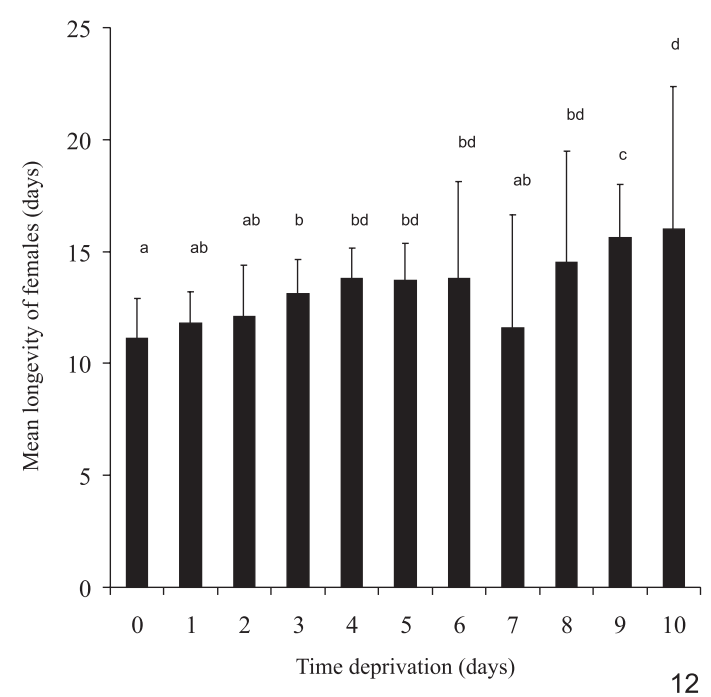

Fig. 12. Mean longevity of Zabrotes subfasciatus females in the different treatments. The results are reported as mean \pm standard deviation of 11 groups with 15 replicates $(\mathrm{P}<0.05$, Kruskal-Wallis test, $\alpha=0.05$ ). Values followed by different letters differed significantly from each other.

The results of egg production and the oviposition peak observed for the control group were similar to those reported by some authors (CARVALHO \& RosSETTO, 1968; MеIк \& DoвIE, 1986), but differed from those obtained by UTIDA (1967) who found the peak of oviposition on the first day of adult life. The present results are more compatible with those of PIMBERT \& POUZAT (1988) in relation to presence of host. Those authors stated that $Z$. subfasciatus females only release sexual attractive pheromone (which is only perceived by the male antennae) when older than two days in presence of host $P$. vulgaris. In absence of host, results differ, as, according to Pimbert \& Pouzat (1988), females only release this pheromone after 6 days of age onwards. The present deprivation experiments showed that the peak of oviposition always occurred on day 1 after introduction of host, followed by a marked decline on the subsequent days.

The results are in agreement with experiments carried out by CAREY et al. (1986) on Diptera Ceratitis capitata (Wiedemann, 1824) and by FLEURY \& Boulétreau (1993) on the parasitoid Trichogramma brassicae (Bezdenko, 1968), who observed a larger number of ovipositions on day 1 after host introduction (when preceded by a period of deprivation), followed by a reduced production on the subsequent days.

The data obtained here demonstrate that $Z$. subfasciatus is able to maintain its reproductive capacity during short periods of host deprivation. This ability might be consequence of good egg retention (up to 5 days of deprivation) and subsequent egg resorption (after 6 days of deprivation), as suggested by Fleury \& Bolétreau (1993) and GreEnBerg et al. (1995) for the Hymenoptera Catolaccus grandis (Burks, 1954) and by RomeIs et al. (2000) for Gryon clavigrallae (Mineo, 1850) in experiments of host deprivation. These investigators proposed that, in relation to the reproductive capacity of any species, the fact that mature eggs might simply not be laid, should be taken into account. This has been observed for some females in which eggs are retained and later resorbed when the specific host is not available. The supply of a host, however, leads to the resumption of oviposition, probably as a result of reduced resorption (VAn Vianen \& Van Lenteren, 1986).

Teixeira Constantino (1956) apud Howe \& CURRIE (1964) observed that Acanthoscelides obtectus (Say, 1831) (Bruchidae) can retain their eggs until an appropriate host is found, with the oviposition rate increasing despite a decline in the duration of oviposition and in the number of eggs laid. The same was observed in the present study, in which the peak of oviposition was higher in the deprived groups than in the control group.

Another aspect to be considered is the fact that egg resorption is higher in older females, as observed for T. brassicae (Fleury \& BouléTREAu, 1993), C. grandis (GREENBERG et al., 1995), Epiphyas postvittana (Walker, 1863) (Foster \& HowARD, 1999) and G. clavigrallae (RomeIs et al., 2000), which is in agreement with the results of the present study.

According to CAREY et al. (1986), the immediate effect of host deprivation is the interruption of the reproductive cycle. The absence of host for prolonged periods of time leads to the postponement of senescence as a mechanism of increasing reproduction and survival of older females. This was observed to occur in the present study in which Z. subfasciatus females, which normally do not produce eggs anymore, or would not survive beyond within a normal cycle, survived longer and laid more eggs than control females of the same age.

The data available in the literature regarding the distribution of $Z$. subfasciatus eggs on $P$. vulgaris grains are contradictory (PIMBERT \& JARRY, 1988). According to UMEYA (1966), the distribution of eggs follows a Poisson pattern (random), whereas UTIDA (1967) reported that eggs laid in an aggregate manner are found throughout the life of Z. subfasciatus females. About 30 to $40 \%$ of the total number of eggs were laid in groups of 2 or more, but their frequency differed each day. This frequency was found to be reduced when females became older, with groups of more than 4 eggs being only observed to occur during the initial phase of adult life. These results are in agreement with the present findings since we observed that $48 \%$ of the total number of eggs in the control group were laid in groups of 2 or more eggs, although there was a predominance of 2 eggs per grain. In the host-deprived groups, the quantity of eggs distributed per grain was larger in the group deprived for 5 days, probably because no egg resorption occurs during this period of deprivation and the ovaries of females are therefore still replete with mature eggs. The number of eggs per grain was smaller in the groups deprived for 8 and 10 days, probably as a consequence of oocyte resorption.

Considering the oviposition behavior of bruchids on wild host plants ( $P$. lunatus Linnaeus, 1753) as a reference, it seems that $Z$. subfasciatus tends to distribute its eggs uniformly on seeds available within the pods (PIMBERT \& JARRY, 1988).

The absence of the host for a given period of time alters the behavior of the female, influencing the distribution of eggs. If the ovipositing time is short, aggregation is more advantageous since females would 
save time by avoiding the recognition of each grain individually. In addition to saving time, the chance of increasing survival of their offspring is higher since larvae originating from aggregated eggs are more likely to survive than those from isolated eggs. UTIDA (1967) also observed that $Z$. subfasciatus mortality is lower in larvae hatching from aggregated eggs than in those hatching from a single egg. The rate of emergence is $91 \%$ for larvae from 6 aggregate eggs versus $80.3 \%$ for offspring from a single egg. These findings are in agreement with the observations on female oviposition made in the present study since they suggest that deprived females show faster oviposition probably in order to increase survival of the offspring. Because females were deprived during a period of higher fecundity and with a high egg load in their ovaries, this also might act as a certain pressure on the females, rendering them less selective and thus leading to the deposition of larger number of eggs on the same grain.

The influence of availability of host on oviposition behavior can be complex, including effects on both egg maturation and processes that do not depend on the quantity of mature eggs, such as, somatic nutritional status of the adult or habitat selection (MINKENBERG et al., 1992). Studies on the oviposition behavior of insects are beginning to show the importance of the quantity of mature oocytes as a determining factor in the variation of foraging intensity, oviposition rate, host acceptance, time of manipulation and aggregation size.

Acknowledgements. To Laércio Massocato and Ana Paula dos Santos for laboratory assistance, and CAPES for financial support.

\section{REFERENCES}

Aluja, M.; Díaz-Fleischer, F. et al. 2001. Effects of age, diet, female density, and the host resource on egg load in Anastrepha ludens and Anastrepha obliqua (Diptera: Tephritidae). Journal of Insect Physiology, Oxford, 47(9):975-988.

Carey, J. R.; Krainacker, D. A. \& Vargas, R. I. 1986. Life history response of female Mediterranean fruit flies, Ceratitis capitata, to periods of host deprivation. Entomologia Experimentalis et Applicata, Dordrecht, 42:159-167.

Carvalho, R. P. L \& Rossetto, J. C. 1968. Biologia de Zabrotes subfasciatus (Bohemann) (Coleoptera, Bruchidae). Revista Brasileira de Entomologia, São Paulo, 13(1):105-117.

Credland, P. F. \& Dendy, J. 1992. Intraespecific variation in bionomic characteres of the Mexican bean weevil, Zabrotes subfasciatus. Entomologia Experimentalis et Applicata, Dordrecht, 65:39-47.

Fleury, F. \& Boulétreau, M. 1993. Effects of temporary host deprivation on the reproductive potential of Trichogramma brassicae. Entomologia Experimentalis et Applicata, Dordrecht, 68:203-210.

Foster, S. P. \& Howard, A. J. 1999. The effects of mating, age at mating, and plant stimuli, on the lifetime fecundity and fertility of the generalist herbivore Epiphyas postvittana. Entomologia Experimentalis et Applicata, Dordrecht, 91:287-295.

Greenberg, S. M.; Morales-Ramos, J. A. et al. 1995. Biological parameters for mass propagation of Catolaccus grandis (Hymenoptera: Pteromalidae). Environmental
Entomology, Lanham, 24(5):1322-1327.

Howe, R. W. \& Currie, J. E. 1964. Some observations on the rates of development, mortality and oviposition of several species of bruchids breeding in stored pulses. Bulletin of Entomological Research, London, 55:437-477.

Leather, S. R. 1984. The effect of adult feeding on the fecundity, weight loss and survival of the pine beauty moth, Panolis flammea. Oecologia, Berlin, 65:70-74.

Meıк, J. \& DobIE, P. 1986. The ability of Zabrotes subfasciatus to attack cowpeas. Entomologia Experimentalis et Applicata, Dordrecht, 42:151-158.

Minkenberg, O. P. J. M.; Tatar, M. \& Rosenheim, J. A. 1992. Egg load as a major source of variability in insect foraging and oviposition behavior. Oikos, Copenhagen, 65:134142.

Pimbert, M. 1985. A model of host plant change of Zabrotes subfasciatus Boh. (Coleoptera: Bruchidae) in a traditional bean cropping system in Costa Rica. Biological Agriculture and Horticulture, San José, 3:39-54.

Pimbert, M. P. \& JARRY, M. 1988. A non-parametric description of the oviposition pattern of Zabrotes subfasciatus inside pods of a wild, Phaseolus lunatus, and a cultivated host plant, Phaseolus vulgaris. Insect Science and its Application, London, 9(1):113-116.

Pimbert, M. P. \& Pierre, D. 1983. Ecophysiological aspects of bruchid reproduction. I. The influence of pod maturity and seeds of Phaseolus vulgaris and the influence of insemination on the reproductive activity of Zabrotes subfasciatus. Ecological Entomology, Oxford, 8:87-94.

Pimbert, M. \& Pouzat, J. 1988. Electroantennogram responses of Zabrotes subfasciatus to odours of the sexual partner. Entomologia Experimentalis et Applicata, Dordrecht, 47:49-53.

Romeis, J.; Shanower, T. G. \& Madhuri, K. 2000. Biology and field performance of Gryon clavigrallae (Hymenoptera: Scelionidae), an egg parasitoid of Clavigralla spp. (Hemiptera: Coreidae) in India. Bulletin of Entomological Research, London, 90:253-263.

Teixeira, I. R. V. \& Zucoloto, F. S. 2003. Seed suitability and oviposition behaviour of wild and selected populations of Zabrotes subfasciatus (Boheman) (Coleoptera: Bruchidae) on different hosts. Journal of Stored Products Research, Winnipeg, 39:131-140.

Thompson, J. N. 1988. Evolutionary ecology of the relationship between oviposition preference and performance of offspring in phytophagous insects. Entomologia Experimentalis et Applicata, Dordrecht, 47:3-14.

Thompson, J. N. \& Pellmyr, O. 1991. Evolution of oviposition behaviour and host preference in Lepidoptera. Annual Review of Entomology, Palo Alto, 36:65-89.

UMEYA, K. 1966. Studies on the comparative ecology of bean weevils. I. On the egg distribution and the oviposition behaviors of three species of bean weevils infesting azuki bean. Research Bulletin Plant Protection Service Japan, Tokio, 3:1-11.

UtidA, S. 1967. Collective oviposition and larval aggregation in Zabrotes subfasciatus (Boh.) (Coleoptera, Bruchidae). Journal of Stored Products Research, Oxford, 2:315322 .

Van Lenteren, J. C.; Van Vianen, A. et al. 1987. The parasite-host relationship between Encarsia formosa Gahan (Hymenoptera: Aphelinidae) and Trialeurodes vaporariorum (Westwood) (Homoptera: Aleyrodidae). XVI. Food effects on oogenesis, oviposition, lifespan and fecundity of Encarsia formosa and other hymenopterous parasites. Journal of Applied Entomology, Berlin, 103:69-84.

Van Vianen, A. \& Van Lenteren, C. 1986. The parasite-host relationship between Encarsia formosa (Hymenoptera, Aphelinidae) and Trialeurodes vaporariorum (Homoptera, Aleyrodidae). XV. Oogenesis and oviposition of Encarsia formosa. Journal of Applied Entomology, Berlin, 102:130-139. 